\title{
Self-reported neck pain is associated with migraine but not with tension-type headache in adolescents
}

Cephalalgia

2014, Vol. 34(II) 895-903

(C) International Headache Society 2014

Reprints and permissions:

sagepub.co.uk/journalsPermissions.nav DOI: I0.II77/0333।024|4523338 cep.sagepub.com

(SAGE

\author{
Astrid Blaschek', Siona Decke ${ }^{2}$, Lucia Albers ${ }^{2}$, \\ Andreas Sebastian Schroeder ${ }^{1,3}$, Steffi Lehmann ${ }^{2}$, \\ Andreas Straube ${ }^{3,4}$, Mirjam N Landgraf ${ }^{1,3}$, Florian Heinen ${ }^{1,3}$ \\ and Rüdiger von Kries ${ }^{2}$
}

\begin{abstract}
Aim: The aim of the present analysis is to confirm or refute the association of neck pain to migraine or tension-type headache and to assess whether this association is independent of other risk factors for headache.

Methods: Secondary school students were invited to complete a questionnaire on headache and lifestyle factors in a cross-sectional study. Neck pain was assessed via (a) a screening question concerning neck pain and (b) denoting affected areas in schematic drawings of the human body.

Results: Absolute increment in prevalence of headache with pain in the shoulder-neck region was between $7.5 \%$ and $9.6 \%$. Gender, grade, stress and lifestyle factors were assessed as potential confounding factors. Nearly all factors were associated with shoulder-neck pain and most with headache. After adjustment for confounders, the association of neck pain with headache was almost completely confined to migraine (OR 2.39; $95 \% \mathrm{Cl}$ I.48-3.85) and migraine + tension-type headache (OR 2.I2;95\% Cl I.50-2.99), whereas the association with isolated tension-type headache was negligible (OR I.22, 95\% Cl 0.87-1.69).

Conclusion: Neck pain is associated with migraine but not with tension-type headache. A possible link between migraine and neck pain may be the cervico-trigeminal convergence of neck and meningeal sensory afferents or a disturbed descending inhibition in migraine.
\end{abstract}

\section{Keywords}

Adolescents, headache, migraine, neck pain, tension-type headache

Date received: I July 2013; revised: 7 October 20I3; 18 November 2013, 2 December 20I3, 9 January 20I4; accepted: II January 2014

\section{Introduction}

Headache is one of the most frequent health complaints among adolescents (1-3). With an overall prevalence of up to $80 \%$ within the last 6 months, migraine and tension-type headache (TTH) are the most frequently reported primary headache syndromes in adolescents $(4,5)$.

Epidemiologic studies in adults and adolescents identified a number of risk factors for headache, which vary by type of headache (6-8). Regarding the role of pain in the neck and shoulder, all studies point to an association with headache (9-12).

There is, however, uncertainty as to whether this association equally exists for migraine and for TTH in adolescence. In univariate analyses most authors
'Department of Paediatric Neurology and Developmental Medicine, Dr. von Hauner Children's Hospital, LMU Munich, Germany ${ }^{2}$ Institute of Social Paediatrics and Adolescent Medicine, LMU Munich, Germany

${ }^{3}$ German Center for Vertigo and Balance Disorders, Munich University Hospital, Germany

${ }^{4}$ Department of Neurology, Klinikum Großhadern, LMU Munich, Germany

\section{Corresponding author:}

Astrid Blaschek, Department of Paediatric Neurology and Developmental Medicine, Dr. von Hauner Children's Hospital, LMU Munich,

Lindwurmstrasse 4, 80337 Munich, Germany.

Email: astrid.blaschek@med.uni-muenchen.de 
found an association with migraine and only few with TTH (11-14). We recently demonstrated a clear association of self-reported neck pain with migraine but not with TTH (5). Identification of specific effects might be of importance as the pathophysiology of migraine may differ from that of TTH (15). To understand the underlying effect of neck pain on headache, it is important to rule out a common cause for both neck pain and headache. The objective of this study therefore was to identify a potentially specific effect of neck pain on either migraine or TTH. Is the effect of neck pain confined to migraine? Is this effect independent of other risk factors for headache (e.g. stress)?

\section{Methods}

\section{Participants}

We used the pre-intervention data from a cluster randomized, prospective intervention study (MUKIS: Münchner Untersuchung zu Kopfschmerzen bei $\overline{\text { Gymnasiasten }}$ - Interventionsstudie). This study was based in the metropolitan area of Munich. The principals of 47 public secondary schools received a letter describing the study, together with a supporting letter from the Bavarian Ministry of Education and Culture. The principals of 12 schools agreed to participate in data collection. They were asked to assign a contact person at their respective school, usually a teacher or school psychologist, who then received a package consisting of further information about the study and exemplary questionnaires for teachers and the families of the potential participants. Questionnaires were handed out during class to all attending students. Students completed the questionnaire during a regular school lesson (45 minutes) in the classroom under supervision of a teacher and at least one member of the Munich Research Group on Headache in Children team (medical doctor or psychologist).

In total, 1674 students (aged between 12 and 19 years) filled in the questionnaires. The final study sample was based on 1445 questionnaires with complete information on gender, grade, type of headache, lifestyle factors (coffee consumption, consumption of drinks containing caffeine, alcohol consumption, smoking, physical activity), stress and pain in the head and neck region. Students reporting headache that could not be classified as migraine, TTH or a combination of both were excluded.

The study was approved by the Data Safety Officer and the Ethic Committee (356/2011) of the Medical Faculty of the Ludwig-MaximiliansUniversity Munich and the Bavarian Ministry of
Education and Culture. Parents and all students older than 14 years gave their written consent to participate in the study.

\section{Headache classification}

Students who responded positively to the screening question 'Did you have any headaches during the last 7 days or 3 month or 6 months?' were classified as headache sufferers. Headache was classified according to the criteria of the German translation of the International Classification of Headache Disorders 2nd edition (ICHD-II) (16) either as migraine, TTH or combined migraine plus TTH as described previously (7).

\section{Lifestyle factors, stress and muscular pain}

The questionnaire included several sub-items of recently published questionnaires on headache in adolescents; for detailed information see references $(5,7,8,17-19)$.

The presence of pain in the head, neck and shoulder region was assessed with the question 'Do you suffer from neck and shoulder pain?' with the ratings 'strongly', 'moderately', 'rarely' or 'not at all' from the Zerssen list (pain in neck and shoulder) (18). In order to identify pain in the neck and shoulder region more specifically, we additionally asked 'Can you identify painful muscles?' and requested participants to mark these locations in each of three drawings showing frontal, back and lateral views of the human body. Pain in the neck and shoulder region was assumed if the students answered the question about pain with yes and marked painful locations in the neck and shoulder region (5).

Consumption of coffee was assessed by the question 'How much coffee do you drink?', 'none', 'one cup per week', 'one cup per day' or 'two or more cups per day'? Students who drink any coffee were categorized as drinking coffee. Consumption of caffeine-containing drinks (energy drinks, cola) was assessed and categorized in the same way. Students who answered the question 'How much alcohol do you drink?' with 'one to three glasses per month', 'one glass per week' or 'more than one glass per week' in any of the categories 'beer', 'wine and champagne' and 'alcoholic mixed drinks, cocktails' were categorized as 'drinking alcohol'. Physical activity was assessed according to the procedure suggested by Kujala et al. (19). Level of activity was categorized as low, moderate or high, students with low level were assigned to the 'inactive group', the others as 'physically active'. Smoking was assessed by the question 'Do you smoke?', which could be answered with 'no', 'yes, less than once a day', 'yes, once a week', 
'yes, more than once a week' or 'yes, daily'. Students who answered with yes were categorized as smokers.

As a global measure for chronic stress experience, we used the chronic stress screening scale consisting of 12 items taken from the TICS (Trier Inventory for Chronic Stress), a 57-item self-report instrument (17). For each item the students had to report their experience within the past 3 months rated on a 5-point scale from 0 (never) to 4 (very often). Individual mean scores for each dimension were calculated and then linearly transformed to age-group related $\mathrm{T}$ norm values (mean 50; $\mathrm{SD} 10$ ). For the individual $\mathrm{T}$ value, it was determined whether the value was within normal range of the T distribution. Stress experience was assumed when the value was above the normal range.

\section{Statistical analysis}

Prevalence of headache and types of headache with binomial confidence intervals were calculated separately for each assessment of pain (reporting pain in neck and shoulder region from the Zerssen list or reporting pain in the neck and shoulder region).

Prevalence of headache and types of headache (number and percentage of students) were additionally assessed by gender, grade and lifestyle factors. Associations between these factors and pain in the neck and shoulder region were assessed. $p$ Values were calculated using chi-square statistics. Potential confounding was assumed if $p$ was less than 0.1 for risk factors associated with both headache and pain in the head and shoulder region. Logistic regression models for headache (any and subtypes) were calculated with stepwise adjustment for potential confounders.

The calculations were performed with the SAS software package (version 9.2, SAS Institute Inc., Cary, NY, USA).

\section{Results}

\section{Prevalence of headache}

A total of 1445 questionnaires were included for analysis with complete information on gender, grade, type of headache, lifestyle factors (coffee consumption, consumption of drinks containing caffeine, alcohol consumption, smoking, physical activity), stress and neck pain. Of the participants, $1201(83.1 \%)$ had experienced headache at least once during the previous 6 months. Of those, $596(41.2 \%)$ reported pure TTH, $136(9.4 \%)$ pure migraine and $469(32.5 \%)$ mixed migraine and TTH.

\section{Pain in head/neck and shoulder}

Table 1 shows the proportion of students with headache and pain or painful areas in neck and shoulder. The absolute increment in prevalence of headache in students reporting pain in the shoulder-neck region was $9.6 \%$ (screening question) and $7.5 \%$ in students who marked painful areas. This difference is mainly a reflection of a higher prevalence of headache in adolescents with migraine or migraine $+\mathrm{TTH}$, as a greater proportion of students with pain in the neck and shoulder region/painful areas suffered from migraine and migraine $+\mathrm{TTH}$. The prevalence of TTH was even higher in students reporting no pain in the neckshoulder region.

To identify potential confounding by other known risk factors, we assessed the associations between gender, grade, stress and lifestyle factors and headache (Table 2). Among all participants with headache, a higher prevalence of headache was observed with female sex, stress, alcohol, coffee consumption and smoking. These risk factors were mostly a reflection of a significantly higher prevalence in headache with a

Table I. Prevalence of headache by reported pain or painful areas in the neck and shoulder region.

\begin{tabular}{|c|c|c|c|c|c|}
\hline & $\begin{array}{l}\text { Total } \\
n=1445\end{array}$ & $\begin{array}{l}\text { Any headache, \% } \\
(95 \% \mathrm{Cl})\end{array}$ & $\begin{array}{l}\text { Migraine, \% } \\
(95 \% \mathrm{Cl})\end{array}$ & $\begin{array}{l}\text { TTH, \% } \\
(95 \% \mathrm{Cl})\end{array}$ & $\begin{array}{l}\text { Migraine + TTH, \% } \\
(95 \% \mathrm{Cl})\end{array}$ \\
\hline \multicolumn{6}{|c|}{ Pain in the neck and shoulder region } \\
\hline Not at all/rarely & 780 & $78.7(75.7-8 \mid .5)$ & $6.8(5.0-8.7)$ & $46.2(42.6-49.7)$ & $25.9(22.9-29.1)$ \\
\hline Moderate/strong & 665 & $88.3(85.6-90.6)$ & $12.6(10.2-15.4)$ & $35.5(31.9-39.3)$ & $40.2(36.4-44.0)$ \\
\hline \multicolumn{6}{|c|}{ Painful areas in the neck and shoulder region } \\
\hline No & 807 & $79.8(77.0-82.6)$ & $6.6(5.0-8.5)$ & $48.2(44.7-51.7)$ & $25.0(22.1-28.2)$ \\
\hline Yes & 638 & $87.3(84.7-89.9)$ & $13.0(10.5-15.9)$ & $32.45(28.8-36.2)$ & $41.85(38.0-45.8)$ \\
\hline
\end{tabular}

$\mathrm{Cl}$, confidence interval; TTH, tension-type headache.

Results are shown in percentage terms with binominal $95 \% \mathrm{Cl}$. 
Table 2. Prevalence of headache by gender, grade, stress and lifestyle factors.

\begin{tabular}{|c|c|c|c|c|c|}
\hline \multicolumn{2}{|c|}{$\begin{array}{l}\text { Demographic and lifestyle factors } \\
\text { Total } n=1445\end{array}$} & \multirow{2}{*}{$\begin{array}{l}\text { Any headache } \\
n=1201 \\
N(\%) \\
523(78.5)\end{array}$} & \multirow{2}{*}{$\begin{array}{l}\text { Migraine } \\
n=136 \\
N(\%) \\
49(7.4)\end{array}$} & \multirow{2}{*}{$\begin{array}{l}\text { TTH } \\
n=596 \\
N(\%) \\
299(44.9)\end{array}$} & \multirow{2}{*}{$\begin{array}{l}\text { Migraine }+ \text { TTH } \\
n=469 \\
N(\%) \\
\text { I } 75(26.3)\end{array}$} \\
\hline Gender & Male $(n=666)$ & & & & \\
\hline & Female $(n=779)$ & $678(87.0)$ & 87 (1 I.2) & $297(38.1)$ & $294(37.7)$ \\
\hline & $p$ & $<0.000 \mathrm{I}$ & $<0.000 \mathrm{I}$ & $<0.05$ & $<0.000 \mathrm{I}$ \\
\hline \multirow[t]{4}{*}{ Grade } & 8. $(n=484)$ & $399(82.4)$ & $50(10.3)$ & $192(39.7)$ & 157 (32.4) \\
\hline & 9. $(n=550)$ & $461)(83.8$ & $52(9.5)$ & $225(40.9)$ & I84 (33.5) \\
\hline & I0. $(n=4 \mid \mathrm{I})$ & $34 \mid(83.0)$ & $34(8.3)$ & $179(45.6)$ & $128(3||)$. \\
\hline & $p$ & $>0.1$ & $>0.1$ & $>0.1$ & $>0.1$ \\
\hline \multirow[t]{3}{*}{ Stress } & No $(n=1104)$ & $894(81.0)$ & 91 (8.2) & $483(43.8)$ & $320(29.0)$ \\
\hline & Any $(n=34 \mathrm{I})$ & $307(90.0)$ & $45(13.2)$ & $113(33.1)$ & I 49 (43.7) \\
\hline & $p$ & $<0.000$ I & $<0.01$ & $<0.001$ & $<0.0001$ \\
\hline \multirow[t]{3}{*}{ Alcohol } & Never $(n=700)$ & $562(80.3)$ & $57(8.1)$ & $281(40.1)$ & $224(32.0)$ \\
\hline & Ever $(n=745)$ & $639(85.8)$ & $79(10.6)$ & $315(42.3)$ & $245(32.9)$ \\
\hline & $p$ & $<0.01$ & $>0.1$ & $>0.1$ & $>0.1$ \\
\hline \multirow[t]{3}{*}{ Coffee } & Never $(n=804)$ & $647(80.5)$ & $61(7.6)$ & $346(43.0)$ & $240(29.9)$ \\
\hline & Ever $(n=64 \mathrm{I})$ & $554(86.4)$ & 75 (II.7) & $250(39.0)$ & $229(35.7)$ \\
\hline & $p$ & $<0.005$ & $<0.01$ & $>0.1$ & $>0.1$ \\
\hline \multirow[t]{3}{*}{ Soft drinks with caffeine } & Never $(n=433)$ & $35 I(8 I . I)$ & $4 \mid(9.5)$ & $179(4 \mid .3)$ & $|3|(30.3)$ \\
\hline & Ever $(n=1012)$ & $850(84.0)$ & $95(9.4)$ & $417(4 \mid .2)$ & $338(33.4)$ \\
\hline & $p$ & $>0.1$ & $>0.1$ & $>0.1$ & $>0.1$ \\
\hline \multirow[t]{3}{*}{ Physical inactivity } & Moderate/high $(n=349)$ & $296(84.8)$ & $35(10.0)$ & I33 (38.1) & $128(36.7)$ \\
\hline & Low $(n=1096)$ & $905(82.6$ & $101(9.2)$ & $463(42.2)$ & $34 \mid(3||)$. \\
\hline & $p$ & $>0.1$ & $>0.1$ & $>0.1$ & $<\mathbf{0 . 1}$ \\
\hline \multirow[t]{3}{*}{ Smoking } & Never $(n=1231)$ & $1012(82.2)$ & $105(8.6)$ & $504(40.9)$ & $403(32.7)$ \\
\hline & Ever $(n=2 \mid 4)$ & I89 (88.3) & $31(14.4)$ & $92(43.0)$ & $60(30.8)$ \\
\hline & $p$ & $<0.05$ & $<0.01$ & $>0.1$ & $>0.1$ \\
\hline
\end{tabular}

TTH, tension-type headache.

$p$ Values were calculated using chi-square statistics. Significant results printed in bold font.

migrainous component (migraine/migraine + TTH). Consistently, there was no association between headache and consumption of caffeine-containing soft drinks, grade or physical inactivity.

In addition, we analyzed whether there was any association with the exposures to pain or painful areas in neck and shoulder, and demographic and lifestyle factors (Table 3). Pain in the neck and shoulder or painful areas was associated with gender, grade, stress, alcohol consumption, coffee and smoking but not with soft drinks containing caffeine. Physical inactivity was associated only with painful areas but not with pain in the head, neck and shoulder region.

To determine whether the association of neck pain and headache is confounded by other risk factors for headache, we applied a logistic regression model with stepwise adjustment for potential confounders. The analysis confirmed the association between neck pain and headache and showed that this is mainly determined by association with migraine and migraine $+\mathrm{TTH}$, while the observed association with isolated TTH could be explained by confounding (Table 4). Stepwise adjustment for gender reduced the OR for migrainous headache by about 9\%. Further adjustment by stress and subsequently by lifestyle factors (alcohol, coffee/caffeine containing soft drinks, physical activity and smoking) accounted for further reductions of, respectively, $8 \%$ and $5 \%$.

\section{Discussion}

Recent publications highlight the influence of neck pain, stress and a variety of lifestyle factors as risk factors for headache with particular importance in migraineurs (5-8). The main finding of the present epidemiologic study was confirmation of the association of neck pain and migraine. This association could not be explained by confounding by stress or lifestyle factors.

This observation substantiates data from our previous large epidemiologic study of healthy secondary 
Table 3. Prevalence of pain by gender, stress and lifestyle factors.

\begin{tabular}{|c|c|c|c|}
\hline Factor & $\begin{array}{l}\text { Total } \\
N=1445\end{array}$ & $\begin{array}{l}\text { Pain in the } \\
\text { neck and shoulder } \\
\text { region (moderate/strong) } \\
N=665\end{array}$ & $\begin{array}{l}\text { Painful areas in } \\
\text { the neck or shoulder } \\
\text { region (yes) } \\
N=638\end{array}$ \\
\hline \multirow[t]{3}{*}{ Gender } & Male $(n=666)$ & 231 (34.68) & $230(34.5)$ \\
\hline & Female $(n=779)$ & $434(55.7 I)$ & $408(52.4)$ \\
\hline & $p$ & $<0.0001$ & $<0.0001$ \\
\hline \multirow[t]{4}{*}{ Grade } & 8. $(n=484)$ & $202(41.74)$ & $224(46.3)$ \\
\hline & 9. $(n=550)$ & $245(44.55)$ & $218(39.6)$ \\
\hline & I0. $(n=4 \mathrm{II})$ & $218(53.04)$ & $196(47.7)$ \\
\hline & $p$ & $<0.005$ & $<0.05$ \\
\hline \multirow[t]{3}{*}{ Stress } & No $(n=1104)$ & $413(39.04)$ & 421 (38.1) \\
\hline & Any $(n=34 I)$ & $234(68.62)$ & $217(63.6)$ \\
\hline & $p$ & $<\mathbf{0 . 0 0 0 I}$ & $<0.0001$ \\
\hline \multirow[t]{3}{*}{ Alcohol } & Never $(n=700)$ & 289 (4I.29) & $293(41.9)$ \\
\hline & Ever $(n=745)$ & $376(50.47)$ & $345(46.3)$ \\
\hline & $p$ & $<0.005$ & $<\mathbf{0 . 1}$ \\
\hline \multirow[t]{3}{*}{ Coffee } & Never $(n=804)$ & $338(42.04)$ & $328(40.8)$ \\
\hline & Ever $(n=64 \mathrm{I})$ & $327(51.01)$ & $310(48.4)$ \\
\hline & $p$ & $<0.001$ & $<0.005$ \\
\hline \multirow[t]{3}{*}{ Soft drinks with caffeine } & Never $(n=433)$ & 204 (47.II) & $189(43.7)$ \\
\hline & Ever $(n=1012)$ & 461 (45.55) & $449(44.4)$ \\
\hline & $p$ & $>0.1$ & $>0.1$ \\
\hline \multirow[t]{3}{*}{ Physical inactivity } & No $(n=349)$ & I74 (49.86) & 174 (49.9) \\
\hline & Yes $(n=1096)$ & 49I (44.80) & $464(42.3)$ \\
\hline & $p$ & $>0.05$ & $<0.05$ \\
\hline \multirow[t]{3}{*}{ Smoking } & Never $(n=|23|)$ & $549(44.60)$ & $528(42.9)$ \\
\hline & Ever $(n=2 \mid 4)$ & II 6 (54.2I) & $110(5 \mathrm{I} .4)$ \\
\hline & $p$ & $<0.01$ & $<0.05$ \\
\hline
\end{tabular}

TTH, tension-type headache.

$p$ Values were calculated using chi-square statistics. Significant results printed in bold font.

school students in Germany (5). Neck pain did not increase the risk for TTH. The apparent inverse association (lower prevalence of TTH in adolescents with neck pain) suggested from the lower proportions of adolescents with TTH in relation to pain in the neck and shoulder region (Table 2) is an artifact caused by the comparator used in the prevalence estimates, which include not only adolescents without headache but also those with other types of headache. The effect of neck pain on migraine is in accordance with most studies on adolescence headache $(6,11-13)$, but none of the previous studies has attempted to rule out confounding by other known risk factors for migraine. The important new finding is that the association between migraine and neck pain cannot be explained by a third common cause such as stress or other lifestyle factors. Therefore it is important to understand the potential mechanism underlying the specific effect of neck pain on migraine.

Pain in head and neck area is a very common finding in the general population and among headache sufferers. In the present study, around $45 \%$ of all participants denoted pain in the neck and shoulder region. We cannot unravel which extracranial pain-sensitive structures are responsible for the sensation of pain in our population. Pain-sensitive structures including skin, muscles, arteries and periosteum give rise to the perception of pain. Also, sensory afferents of the connective tissue (extracellular matrix) around and within scalp muscles give rise to the perception of pain, a finding reported first by Hinsey in 1928 (20). The significantly increased co-occurrence of neck pain in children with migraine might have several potential explanations. The brain is generally susceptible to exogenous and 
Table 4. Association of pain and gender, stress and lifestyle factors.

\begin{tabular}{|c|c|c|c|c|c|}
\hline Odds ratio and $95 \% \mathrm{Cl}$ & $\begin{array}{l}\text { Any headache } \\
N=|20|\end{array}$ & $\begin{array}{l}\text { Migraine } \\
N=136\end{array}$ & $\begin{array}{l}\text { TTH } \\
N=596\end{array}$ & $\begin{array}{l}\text { Migraine }+ \text { TTH } \\
N=469\end{array}$ & $\begin{array}{l}\text { Migraine }+ \text { TTH } \\
\text { \&Migraine } \\
N=605\end{array}$ \\
\hline \multicolumn{6}{|c|}{ Pain in the neck and shoulder region (moderate/strong vs. not at all/scarcely) } \\
\hline Univariate analysis & $2.04(1.52-2.72)$ & $3.44(2.22-5.33)$ & $1.40(1.02-1.91)$ & $2.81(2.03-3.89)$ & $2.94(2.15-4.03)$ \\
\hline \multicolumn{6}{|l|}{ Multivariate analysis adjusted for } \\
\hline Gender & $1.85(1.37-2.48)$ & $3.06(1.96-4.79)$ & $1.32(0.96-1.82)$ & $2.51(1.80-3.50)$ & $2.61(1.90-3.60)$ \\
\hline Gender + stress & I.7I ( $(1.26-2.32)$ & $2.7 I(I .7 I-4.30)$ & $1.27(0.91-1.76)$ & $2.26(1.61-3.17)$ & $2.37(1.7 \mid-3.28)$ \\
\hline Gender + stress + lifestyle factors & $1.62(1.19-2.20)$ & $2.39(1.48-3.85)$ & $1.22(0.87-1.69)$ & $2.12(1.50-2.99)$ & $2.20(1.58-3.07)$ \\
\hline \multicolumn{6}{|c|}{ Painful areas in the neck or shoulder region (yes vs. no) } \\
\hline Univariate analysis & $1.74(1.30-2.33)$ & $3.15(2.04-4.87)$ & $1.07(0.78-1.47)$ & $2.66(1.93-3.67)$ & $2.76(2.02-3.77)$ \\
\hline \multicolumn{6}{|l|}{ Multivariate analysis adjusted for } \\
\hline Gender & $1.59(1.18-2.13)$ & $2.74(1.75-4.28)$ & $\mathrm{I} .02(0.74-\mathrm{I} .40)$ & $2.44(1.76-3.40)$ & $2.48(I .8 I-3.4 I)$ \\
\hline Gender + stress & $1.48(1.10-2.00)$ & $2.52(1.60-3.97)$ & $0.98(0.7 \mathrm{I}-1.35)$ & $2.22(1.58-3.10)$ & $2.27(1.65-3.13)$ \\
\hline Gender + stress + lifestyle factors & $1.42(1.05-1.92)$ & $2.26(1.42-3.60)$ & $0.95(0.68-1.31)$ & $2.10(1.50-2.95)$ & $2.14(1.55-2.97)$ \\
\hline
\end{tabular}

$\mathrm{Cl}$, confidence interval; TTH, tension type headache. Results are shown as OR with binominal $95 \% \mathrm{Cl}$. Significant results are printed in bold font.

endogenous triggers with migraineurs exhibiting an interictal abnormal processing of sensory information in neurophysiologic studies (for review see (21)). In summary, the analysis of interictal cortical excitability with electrophysiology, transcranial magnetic stimulation and fMRI revealed a hyperexcitable (less habituated) cortex as the most consistent finding in migraine.

The mechanism underlying the dysfunctional regulation is largely unknown and a major open issue (22). A schematic representation of potential neuronal structures involved in migraine pain is shown in Figure 1. It has been suggested that a central sensitization within the cervico-trigeminal system occurs as a consequence of prolonged peripheral nociceptive input from intramuscular areas (23). A prolonged increase of regional muscle tone via the limbic system may at the same time potentiate pain facilitation from the brain stem to the spinal dorsal horn (24). It is interesting that in patients with strict unilateral migraine, so-called active muscular trigger points are found more often in the ipsilateral pericranial muscles (25). Sensory information from somatic nociceptive, perivascular and meningeal sensory afferents terminate in the trigeminocervical complex (TCC) (Figure 1). The TCC is composed of $\mathrm{C} 1$ and $\mathrm{C} 2$ dorsal horns of the cervical spinal cord and the caudal part of the spinal trigeminal nucleus. From there direct ascending connections to brainstem (e.g. periaqueductal grey), thalamic and hypothalamic areas are made, which in turn are connected to cortical sensory areas (e.g. S1, S2 and insular cortex, as part of the so called pain matrix) (26). The TCC receives modulating descending input from periaqueductal grey, hypothalamic neurons. Furthermore, direct corticotrigeminal projections exists to promote a top-down nociceptive regulation. With lack of habituation being the principal and most reproducible interictal abnormality in migraine patients, dysfunctional descending inhibition has been proposed (24). Recent TMS studies point to deficits in the ability to dynamically maintain a balance between cortical excitation and inhibition $(27,28)$. Deficient cortical regulation may be the cause of a higher variability in visual cortex excitability observed in children with migraine, in particular during the hours preceding an attack (29).

In summary, migraine patients show a hypersensitivity to sensory stimuli and dysfunctional modulatory pathways within the sensory system. In migraine, a hyper excitable brain with defective habituation is stimulated by exogenous and endogenous triggers to start a cascade of temporary/functional neurochemical changes (e.g. cortical spreading depression, activation of the trigeminovascular system) that generate clinical symptoms of migraine. Intrinsic nociceptive afferents of head and neck might, therefore, represent the sensory contribution to the observed association of neck pain and migraine. To date, the mechanism underlying this dysfunction remains largely unknown.

Our study was focused on the association between neck pain and headache. Confounding by established risk factors for headache such as gender, grade, stress and lifestyle factors could be excluded, although most of those factors were associated with different types of headache and all with neck pain. We hypothesize that migraineurs are especially sensitive to them. Studies on migraine revealed an increased susceptibility to other types of pain probably resulting from the intensive experience of pain in migraine attacks $(8,30)$. Increased intramuscular activity secondary to psychological stress is likely to be of relevance in this respect, because the stress condition may cause a prolonged increase of regional muscle tone via the limbic system followed by functional changes in extracellular matrix 


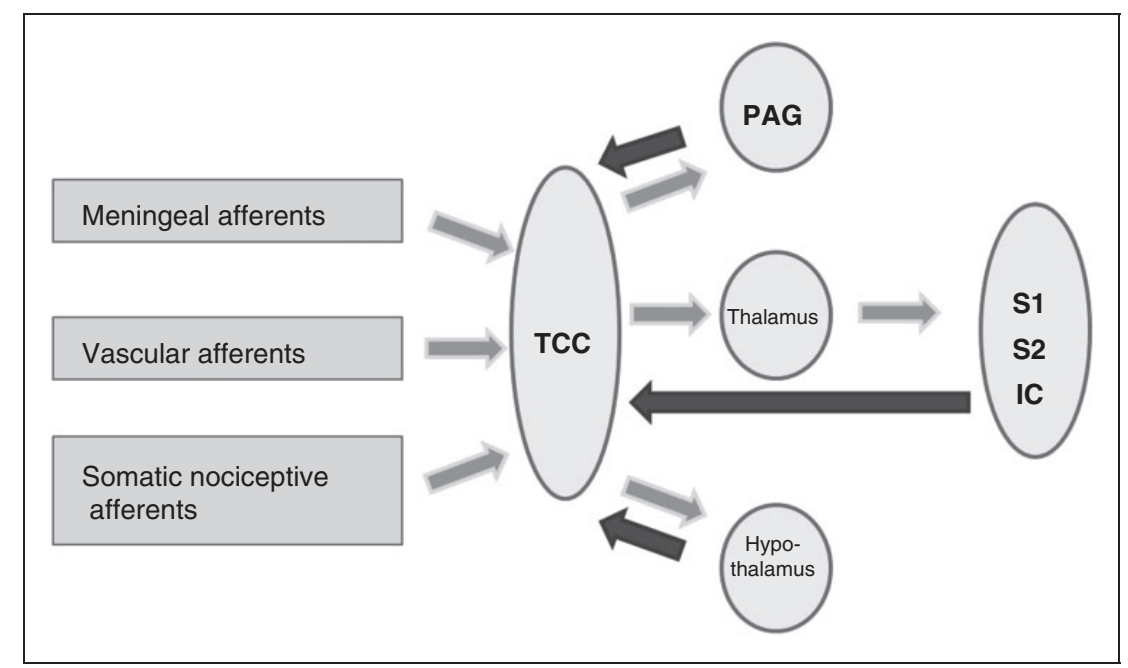

Figure I. Schematic representation of neuronal structures involved in migraine pain. Afferent pathways are depicted in grey arrows, regulatory input in black. TCC trigeminocervical complex $(\mathrm{Cl}$ and $\mathrm{C} 2$ dorsal horns of the cervical spinal cord and caudal part of the spinal trigeminal nucleus); PAG (periaqueductal gray); SI (primary somatosensory cortex); S2 (secondary somatosensory cortex), IC (insular cortex).

characteristics and at the same time potentiate pain facilitation from the brain stem to the spinal dorsal horn (24). In addition, migraine patients show hypersensitivity to sensory stimuli and dysfunctional modulatory pathways within the sensory system.

\section{Strength and limitations}

The major strength of our study is its population-based data collection with a comparatively low number of excluded questionnaires $(13.7 \%)$, thus sampling bias seems unlikely. With the large number of participants, it was possible to differentiate between types of headache and to determine headache-type-specific associations between neck pain and headache.

There are some limitations of the present study. Classifications of types of headache were not validated by physicians' diagnoses, but were based on a validated self-administered questionnaire. This might have resulted in comparatively high estimates of headache prevalence, particularly for TTH and mixed headache. However, a number of studies have found reasonable sensitivity, specificity and predictive values for headache screening questionnaires (31-33). Valentinis et al. used a very similar questionnaire which incorporated all items required for diagnosing migraine according to the ICHD-II criteria. The questionnaire-based diagnosis was validated against the gold standard diagnosis by a headache specialist. Results showed that the questionnaire-based migraine diagnosis had a sensitivity of $67.3 \%$, and a specificity of $100 \%$.The Cohen's kappa coefficient was 0.66 denoting a good level of agreement between both analyses (31). Out of another large population-based headache study, 70 children with questionnaire-based diagnosis of migraine, TTH or no headache each were randomly selected to confirm headache diagnosis by face to face interview. The questionnaire based diagnosis was confirmed in $84 \%$ (migraine), $93 \%$ (TTH) and $84 \%$ (no headache) of participants (11).

The questionnaire used is an established instrument for assessing frequency and localization of pain among children and adolescents. It has been used in several other studies $(2,4,5,34,35)$ and has been clearly shown to be suitable for adolescents.

Localization of pain was only self-reported, which may have resulted in some misclassification or failure to correctly specify the 'true' pain sensitive area (see methods). Validation of self-reported pain spots by physical examination was not possible because of the strictly anonymous data collection. However, former investigations have used comparable questionnaires $(5,6,13,36)$ and demonstrated a close correlation between self-reported pain areas and results of clinical examination (e.g. $(11,37))$. Additionally, we applied independent approaches to identify 'pain' in the neck and shoulder region by asking about pain and by asking to mark the respective region on a schematic drawing of the human body. Both approaches yielded similar findings.

\section{Conclusion}

The main finding of the present epidemiologic study was the confirmation of the association of neck pain and migraine, which could not be explained by stress 
or lifestyle factors. Pain in the neck and shoulder region is common in adolescents. In migraineurs, however, there might be specific susceptibility to pain in this area prompting migraine attacks. A possible link between migraine and neck pain may be the cervico- trigeminal convergence of neck and meningeal sensory afferents or a disturbed descending inhibition in migraine. Efforts for pain relief in the neck and shoulder region might therefore be a means for prevention of migraine.

\section{Clinical implications}

- Neck pain is independently associated with migraine but not with tension-type headache.

- Efforts for pain relief in the neck and shoulder region might therefore be a means for prevention of migraine.

- A possible link between migraine and neck pain might be the cervico-trigeminal convergence of neck and meningeal sensory afferents or a disturbed descending inhibition in migraine. As a result, a specific susceptibility to pain in the neck and shoulder region might arise leading to migraine attacks.

\section{Funding}

The study was supported by an unrestricted personal grant of the German Headache and Migraine Society (DMKG) to S. L.

\section{Conflict of interest}

None declared.

\section{Acknowledgements}

We thank all participants for their time and efforts. We also thank the contact persons at the participating schools for their effort in preparation of the data collection. We thank the Bavarian State Ministry for Education and Culture for understanding and support. The authors gratefully acknowledge the assistance of Jörg Urban in the preparation of this manuscript.

\section{References}

1. Hershey AD. Pediatric headache: Update on recent research. Headache 2012; 52: 327-332.

2. Roth-Isigkeit A, Thyen U, Raspe HH, et al. Reports of pain among German children and adolescents: An epidemiological study. Acta Paediatr 2004; 93: 258-263.

3. Kroner-Herwig B, Heinrich M and Morris L. Headache in German children and adolescents: A populationbased epidemiological study. Cephalalgia 2007; 27: 519-527.

4. Fendrich K, Vennemann M, Pfaffenrath V, et al. Headache prevalence among adolescents-The German DMKG headache study. Cephalalgia 2007; 27: 347-354.

5. Blaschek A, Milde-Busch A, Straube A, et al. Self-reported muscle pain in adolescents with migraine and tension-type headache. Cephalalgia 2012; 32: 241-249.

6. Grimmer K, Nyland L and Milanese S. Repeated measures of recent headache, neck and upper back pain in Australian adolescents. Cephalalgia 2006; 26: 843-851.

7. Milde-Busch A, Blaschek A, Borggrafe I, et al. Associations of diet and lifestyle with headache in high-school students: Results from a cross-sectional study. Headache 2010; 50: 1104-1114.
8. Milde-Busch A, Blaschek A, Heinen F, et al. Associations between stress and migraine and tension-type headache: Results from a school-based study in adolescents from grammar schools in Germany. Cephalalgia 2011; 31: 774-785.

9. Bendtsen L and Fernandez-de-la-Penas C. The Role of Muscles in Tension-Type Headache. Curr Pain Headache Rep 2011; 15: 451-458.

10. Blau JN and MacGregor EA. Migraine and the neck. Headache 1994; 34: 88-90.

11. Anttila P, Metsahonkala L, Mikkelsson M, et al. Muscle tenderness in pericranial and neck-shoulder region in children with headache. A controlled study. Cephalalgia 2002; 22: 340-344.

12. Metsahonkala L, Anttila P, Laimi K, et al. Extracephalic tenderness and pressure pain threshold in children with headache. Eur J Pain 2006; 10: 581-585.

13. Anttila P, Metsahonkala L, Aromaa M, et al. Determinants of tension-type headache in children. Cephalalgia 2002; 22: 401-408.

14. Laimi K, Salminen JJ, Metsahonkala L, et al. Characteristics of neck pain associated with adolescent headache. Cephalalgia 2007; 27: 1244-1254.

15. Kelman L. The biological basis of headache. Exp Rev Neurother 2011; 11: 363-378.

16. The International Classification of Headache Disorders: 2nd edition. Cephalalgia 2004; 24 Suppl 1: 9-160.

17. Schulz P. Trier inventory of chronic stress. Göttingen: Hogrefe, 2004.

18. Zerssen D and Petermann F. B-LR-Beschwerden-ListeRevidierte Fassung. Göttingen: Hogrefe, 2011.

19. Kujala UM, Taimela $S$ and Viljanen T. Leisure physical activity and various pain symptoms among adolescents. Br J Sports Med 1999; 33: 325-328.

20. Hinsey JC. Observations on the innervation of blood vessels in skeletal muscles. J Comp Neurol 1928; 47: 23-65.

21. Pietrobon D and Moskowitz MA. Pathophysiology of migraine. Ann Rev Physiol 2013; 75: 365-391.

22. Coppola G, Pierelli $F$ and Schoenen J. Is the cerebral cortex hyperexcitable or hyperresponsive in migraine? Cephalalgia 2007; 27: 1427-1439. 
23. Bendtsen L. Central sensitization in tension-type headache-possible pathophysiological mechanisms. Cephalalgia 2000; 20: 486-508.

24. Sauro KM and Becker WJ. The stress and migraine interaction. Headache 2009; 49: 1378-1386.

25. Fernandez-de-Las-Penas C, Cuadrado ML and nd Pareja JA. Myofascial trigger points, neck mobility and forward head posture in unilateral migraine. Cephalalgia 2006; 26 : 1061-1070.

26. Noseda R, Constandil L, Bourgeais L, et al. Changes of meningeal excitability mediated by corticotrigeminal networks: a link for the endogenous modulation of migraine pain. J Neurosci 2010; 30: 14420-14429.

27. Antal A, Lang N, Boros K, et al. Homeostatic metaplasticity of the motor cortex is altered during headache-free intervals in migraine with aura. Cerebral Cortex 2008; 18 : 2701-2705.

28. Siniatchkin M, Sendacki M, Moeller F, et al. Abnormal changes of synaptic excitability in migraine with aura. Cerebral Cortex 2012; 22: 2207-2216.

29. Siniatchkin M, Reich AL, Shepherd AJ, et al. Peri-ictal changes of cortical excitability in children suffering from migraine without aura. Pain 2009; 147: 132-140.

30. Abu-Arafeh I and Russell G. Prevalence and clinical features of abdominal migraine compared with those of migraine headache. Arch Dis Child 1995; 72: 413-417.

31. Valentinis L, Valent F, Mucchiut M, et al. Migraine in adolescents: validation of a screening questionnaire. Headache 2009; 49: 202-211.

32. Zarifoglu M, Karli $\mathrm{N}$ and Taskapilioglu O. Can ID Migraine be used as a screening test for adolescent migraine? Cephalalgia 2008; 28: 65-71.

33. Hershey AD, Winner P, Kabbouche MA, et al. Use of the ICHD-II criteria in the diagnosis of pediatric migraine. Headache 2005; 45: 1288-1297.

34. Roth-Isigkeit A, Ellert U and Kurth BM. [Assessment of pain in The Child and Adolescent Health Survey]. Gesundheitswesen 2002; 64(Suppl 1): S125-S129.

35. Milde-Busch A, Heinrich S, Thomas S, et al. Quality of life in adolescents with headache: Results from a population-based survey. Cephalalgia 2010; 30: 713-721.

36. Smith L, Louw Q, Crous L and Grimmer-Somers K. Prevalence of neck pain and headaches: Impact of computer use and other associative factors. Cephalalgia 2009; 29: 250-257.

37. Laimi K, Vahlberg T, Salminen J, et al. Does neck pain determine the outcome of adolescent headache? Cephalalgia 2007; 27: 244-253. 